ISSN 1112-9867

Available online at

http://www.jfas.info

\title{
COMPARING DIFFERENT THINKING STYLES AND MARITAL SATISFACTION AMONG ENGINEERS OF URBAN AND NONURBAN AREAS
}

\author{
Y. Asrami
}

Vahdat Yazdanpanah Asrami, Bachelor of Science in Civil Engineering

Published online: 13 June 2016

\begin{abstract}
The purpose of the present study was to compare different thinking styles and marital satisfaction among engineers of urban and nonurban areas. The design of this study was casual-comparative. The sample population of this study consisted of the engineers who were members of engineers' society of Sari city among which two samples of 138 urban engineers and 112 nonurban engineers were chosen randomly. Enrich's Marital Satisfaction Questionnaire and Sternberg's Thinking Styles were the instruments of this study. Data were analyzed using descriptive statistics, independent t-test and Loon test. The results of this study indicated that there is a significant difference between thinking styles, marital satisfaction and job burnout among engineers of urban and nonurban areas.
\end{abstract}

Keywords: thinking styles; marital satisfaction; engineer.

Author Correspondence, e-mail: vahdat.yazdanpanah@gmail.com

doi: $\underline{\text { http://dx.doi.org/10.4314/jfas.8vi2s.82 }}$

\section{INTRODUCTION}

Marital satisfaction conducts the communication between spouses and children. Marital satisfaction exists when the present status of the individual in the marital relationship corresponds with what he or she expects. On the other hand, marital dissatisfaction happens when the present status of the individual does not correspond with expectations (Shifren et al., 2008). Relationship with the partner is the central aspect of individual's emotional and social life (Barton et al., 2006). Marital dissatisfaction damages the ability of parents to have a 
satisfactory relationship with children and others out of the family (Fooladi, 2004). In recent years, feeling safe, calm and cordial relations between spouses has become slow and the family has been undergone unpleasant procedures (Farhoudian, 2005). Loretz et al. (2006) consider marital relationships as a process in which spouses exchange feelings and thoughts through verbal and non-verbal acts such as listening, facial expressions and gestures. Marital life satisfaction has an important role in survival and education of the next generation (Ferasat, 2002). Gutman (1998) considers marital satisfaction as an element resulting from feelings associated with experienced pleasure, satisfaction and joy by spouses. Elise (1992) considers the role of marital satisfaction as an important element and believes that ignoring the interests of other party leads to discouragement and failure in marital life. According to Gutman (1998), satisfaction comes in three main levels: couples satisfaction of marriage, family life satisfaction and overall life satisfaction. However, it can be accepted that marital satisfaction is the result of satisfaction and spouses' compatibility in different aspects of life and provides the strength of the family and parental health (Shahi et al., 2011). There are different factors affecting the satisfaction of spouses such as mutual respect, matched beliefs, marriage age, duration of mutual life, relatives and acquaintances, religious, business conditions, the number and health status of children and how to solve problems as well as thinking styles (Halford, 2005).

People can have different performances in business stages regarding how much their job environment is or is not consistent with their life style. Despite numerous and detailed definitions of ability, thinking styles are important as much as ability; since, social and emotional constructions as well as intellectual functions and in fact, different aspects of intelligence, expand our imagination for what people can do. On the other hand, thinking styles approximate our imagination to what people prefer rather than what they are able to do. When person's thinking styles profile has a good correspondence with the environment, will process. But, when the correspondence is not good and sufficient, there would be some consequences. Depending to this condition that how and to what extend individual's profile is consistent with the environmental expectations and how does one assess the environment, his or her performance quality appears over the course of employment (Esternberg, 2001). Robert Esternberg has called different ways in information processing as thinking styles. According to him, thinking style is the preferred method of thinking. Thinking style is not an ability; rather, how the individual uses his or her capabilities. The ability points to coping with the work in a good way while style points to this fact that how the individual likes to do something. People with the same capabilities may have different styles. Different styles are 
neither good nor bad; in fact, they are different. Esternberg in the framework of "mental egoism theory", has identified thirteen main thinking styles including legislative, executive, judicial, holistic, liberal, conservative, monarchy, anarchy, oligarchs, hierarchical, internal and external. Each of these terms has its own definition. The main assumption of Esternberg's mental egoism theory is that different governments in the world have not appeared by chance; rather, are a reflection of external events that occur in peoples' mind. As people with different styles (with a variety of governments) control and manage others, they can control and manage themselves too. People, like cities, states or even countries, need to control and manage themselves (Castels, 2001). The findings and results of previous studies indicate that research on thinking styles, increases understanding and awareness of colleagues and helps to improve organizational communication; as a result, provides significant opportunities for organizational development of people (Herison and Bramson, 2002). Denilson and Dlisi (2001) in a study on thinking styles of senior managers and IT basics of The United States found that low level managers have analytical-oriented thinking style while high level managers have holistic style, meaning idealism and pragmatism that are distinguished by having a holistic view and flexibility in order to cope with complexities and concentrating on strategic innovations. In 1991, a study was conducted on examining the effective factors on managers' innovation and the results indicated that there is a $25 \%$ correlation between thinking styles and innovation of managers (Ford, 1999).

Due to the need of organizations to provide physical and mental health of staff and examining the effective factors on them, the present study wants to answer this question that are thinking styles and marital satisfaction different among engineers working in urban and nonurban areas?

\section{METHODOLOGY}

The design of the present study is casual-comparative. The sample population of this study consisted of all married male engineers who were members of engineers' society of Sari city that consisted of 850 people among which, 469 people are working in urban area and 381 people in nonurban area. Through random sampling method, 250 people (138 of urban area and 112 from nonurban area) were chosen. The instruments used in this study consisted of Enrich's Marital Satisfaction Questionnaire and Stenberg's Thinking Styles.

Enrich's Marital Satisfaction Questionnaire: the main form of this questionnaire consisted of 115 items that have 12 subscales that Elson et al. (1993) prepared its short form that 
consisted of 47 items with 9 subscales including topics such as personality, marital communication, conflict resolution, financial management, activities related to leisure, sexual relations, marriage and children, relative and friends and religious orientations (Ahadi, 2007). This scale consists of 47 items that the subjects specify their agreement with each item on a five-point Likert scale (strongly disagree, disagree, no idea, agree and strongly agree). The reliability of the short-form questionnaire was calculated using Cronbach's alpha as 0/92.

Also, its validity was calculated as 0/85 and 0/95 (Abbasi, 2008). In Iran, this scale has been used in different studies that its reliability has been reported as between 0/41 and 0/94 using Cronbach's alpha. In order to assess the reliability of this test, Pearson's correlation coefficient was calculated by test-retest method (with 1 week interval) and the results were 94\% for women, $93 \%$ for man and $94 \%$ for all (men and women). This questionnaire has a correlation of $0 / 41$ to $0 / 60$ with different scales of family satisfaction questionnaire that indicates good construct validity of the questionnaire (Vigel et al., 2005).

Sternberg's Thinking Styles Questionnaire: thinking styles are interpreted as a score that is obtained through a shortened version of Sternberg's thinking styles questionnaire that has been set by Alborzi and Ostovar (2007). This questionnaire evaluates three thinking styles that consist of 13 components. The first thinking style is composed of 5 components and is evaluated by 23 items. Its forming components include judicial thinking style (5 items), legislative thinking style (4 items), and general thinking style (4 items), hierarchical thinking style (5 items) and liberal thinking style (5 items). Scoring each item is based on seven-point Likert scale. Point 1 belongs to the option that "it is not true about me" and point 7 states that "it is absolutely true about me". Alborzi and Ostovar confirmed the validity of thinking styles questionnaire through factor analysis. In this study, the first item consists of different thinking styles including legislative, judicial, general, liberal and internal. The second item includes executive, local, conservative, hierarchical and external and the third item consists of categorical and uniaxial thinking styles. Also, the correlation pattern between the scores obtained from the components of this questionnaire was consistent with Sternberg's mental self-government theory which was indicative of its construct validity. Alborzi and Ostovar examined this item of questionnaire and reported its Cronbach's alpha for the thinking styles of this study ranging between $0 / 58$ and $0 / 82$. These results are consistent with the results of Sternberg's thinking style questionnaire (Alborzi and Ostovar, 2007). In the present study, the Cronbach's alpha was used to calculate the reliability which was 0/75.

In this study, in order to collect data and data analysis, SPSS18 software was used. In descriptive statistics such as drawing tables based on the frequency as well as analyzing the 
data, inferential statistics methods such as t-test and Loon test were used.

\section{RESULTS}

Descriptive parameters (frequency, percentage, mean and standard deviation) and research variables (marital satisfaction and thinking styles) are presented in Tables 1-2.

Table 1. Frequency distribution of sample volume according to the place of employment

\begin{tabular}{|c|c|c|}
\hline & & $\begin{array}{l}\text { Statistical } \\
\text { indicators }\end{array}$ \\
\hline percentage & & $\begin{array}{l}\text { Group } \\
\mathrm{s}\end{array}$ \\
\hline $55 / 2$ & 138 & $\begin{array}{l}\text { Engineers working } \\
\text { in } \\
\text { urban area }\end{array}$ \\
\hline $44 / 8$ & 112 & $\begin{array}{c}\text { Engineers working in } \\
\text { nonurban area }\end{array}$ \\
\hline 100 & 250 & total \\
\hline
\end{tabular}

Table 2. Calculating the descriptive indicators of research variables according to the place of work

\begin{tabular}{|c|c|c|c|c|c|}
\hline Maximum & Minimum & SD & mean & number & Statistical indicators \\
\hline score & score & & & & \\
\hline
\end{tabular}




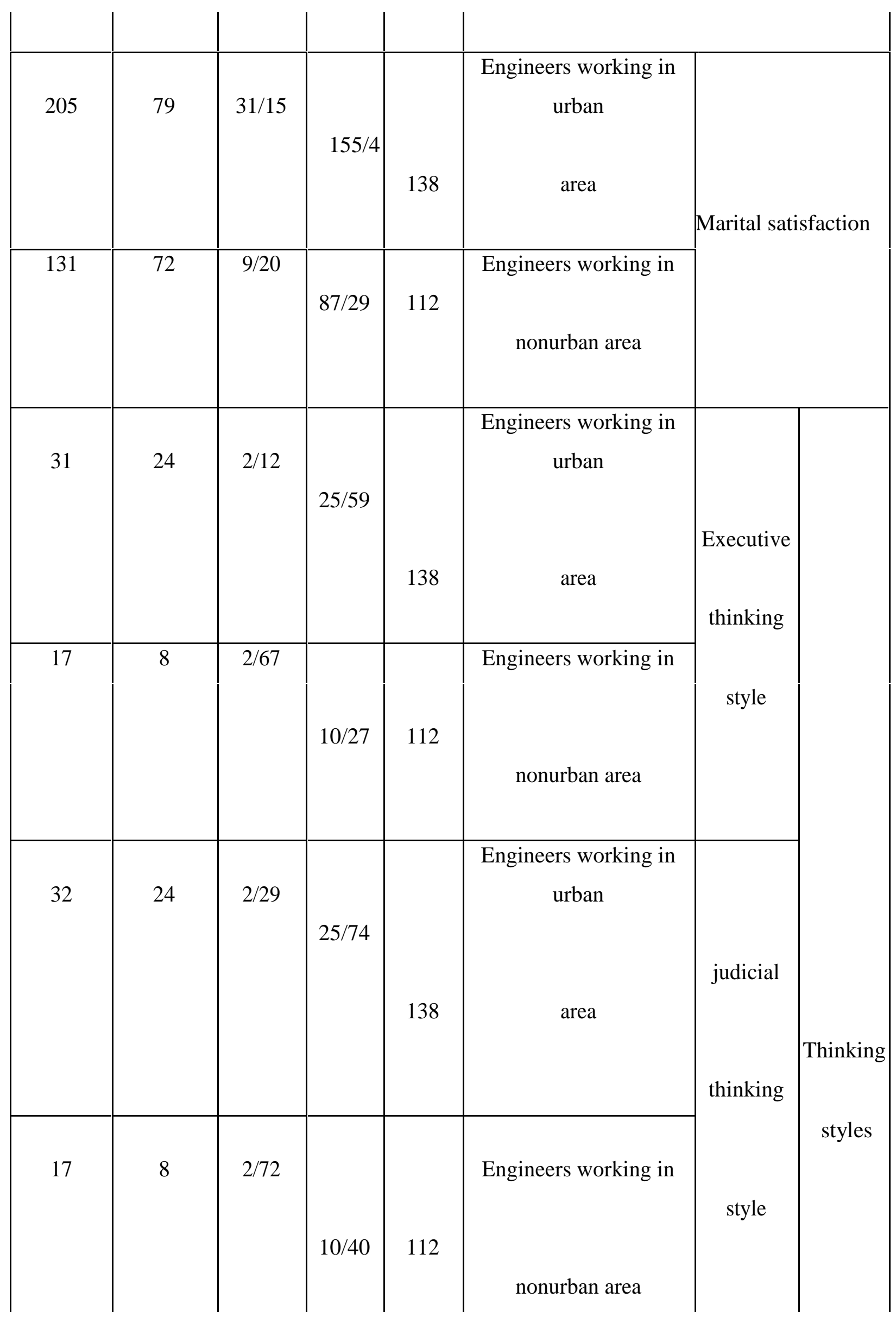




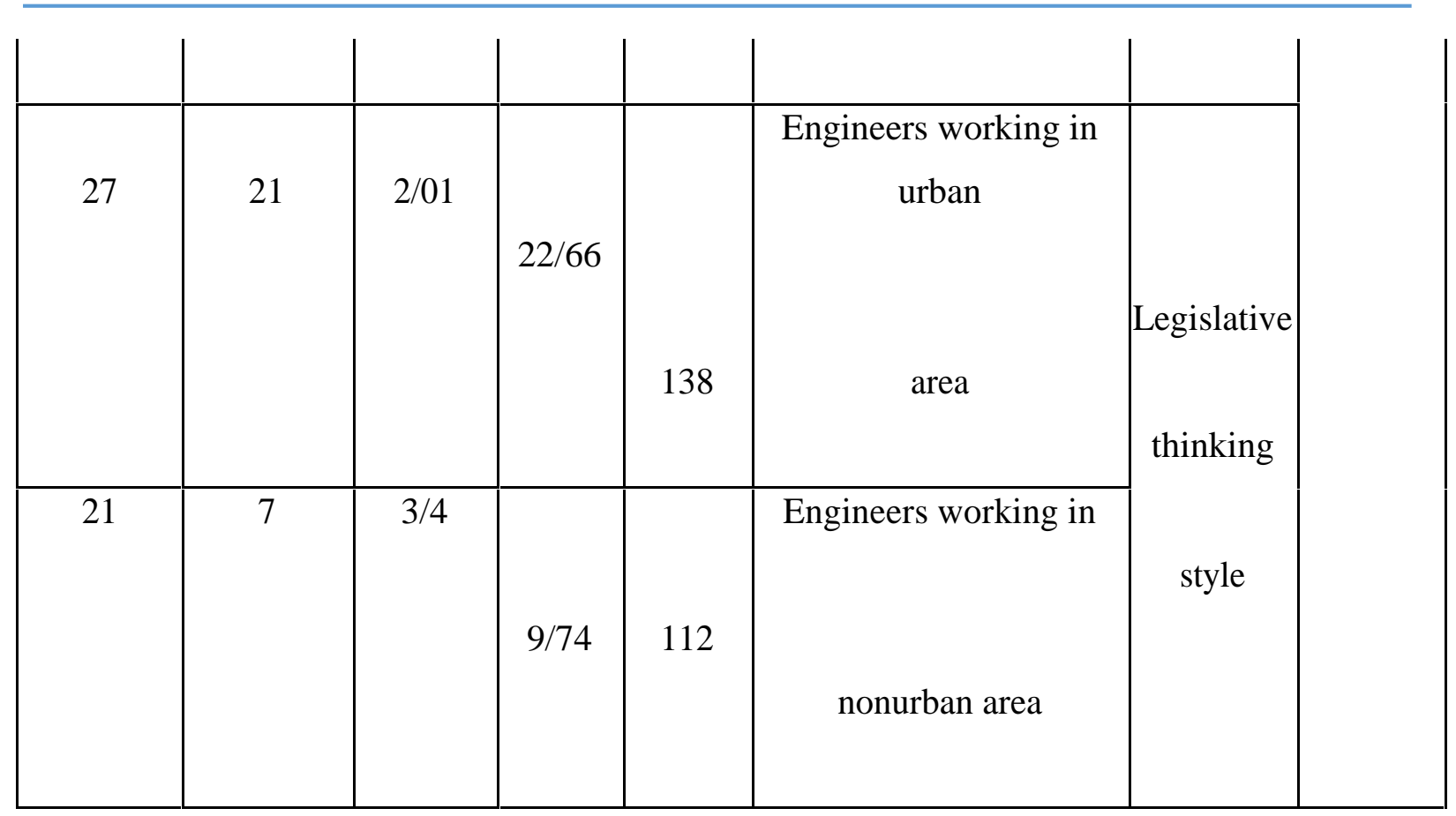

The results of hypothesis testing are presented in tables 3, 4 and 5 .

Hypothesis 1: The marital satisfaction is different between engineers working in urban areas and engineers working in nonurban areas.

\begin{tabular}{|c|c|c|c|c|c|c|c|}
\hline \multirow{2}{*}{$\begin{array}{l}\text { Signific } \\
\text { ance } \\
\text { level }\end{array}$} & \multirow{2}{*}{$\begin{array}{c}\text { Degree } \\
\text { of } \\
\text { freedom }\end{array}$} & \multirow[b]{2}{*}{ t-value } & \multirow[b]{2}{*}{ SD } & \multirow[b]{2}{*}{ mean } & \multicolumn{2}{|c|}{ Loon test } & \multirow[t]{2}{*}{ Statistical indicators } \\
\hline & & & & & $\begin{array}{l}\text { Significa } \\
\text { nce level }\end{array}$ & $\mathrm{F}$ & \\
\hline \multirow[b]{2}{*}{$0 / 00$} & \multirow[b]{2}{*}{$153 / 2$} & \multirow[b]{2}{*}{$23 / 64$} & $31 / 15$ & $155 / 4$ & \multirow[b]{2}{*}{$0 / 00$} & \multirow[b]{2}{*}{$95 / 12$} & $\begin{array}{c}\text { engineers working in urban } \\
\text { areas }\end{array}$ \\
\hline & & & $9 / 20$ & $87 / 29$ & & & $\begin{array}{l}\text { engineers working in } \\
\text { nonurban } \\
\text { areas }\end{array}$ \\
\hline
\end{tabular}


According to the significance level of Loon test (0/01) that is less than $0 / 05$, assuming the equality of variance between the groups is rejected. Therefore, second row t-test data were used for analysis. As a result, there is a significant difference between the marital satisfaction of engineers working in urban areas and engineers working in nonurban areas.

Hypothesis 2: Thinking styles are different among engineers working in urban areas and engineers working in nonurban areas.

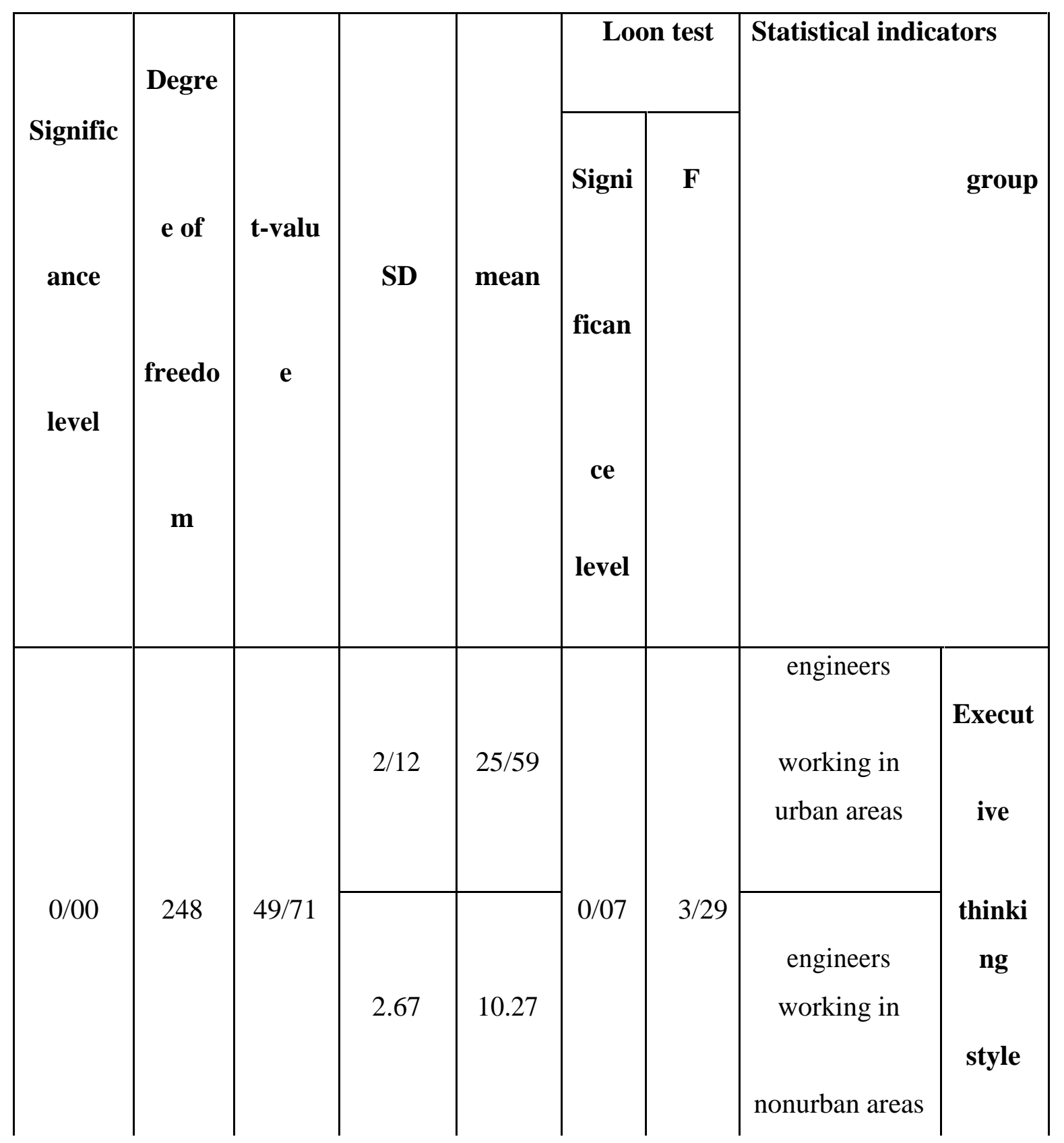




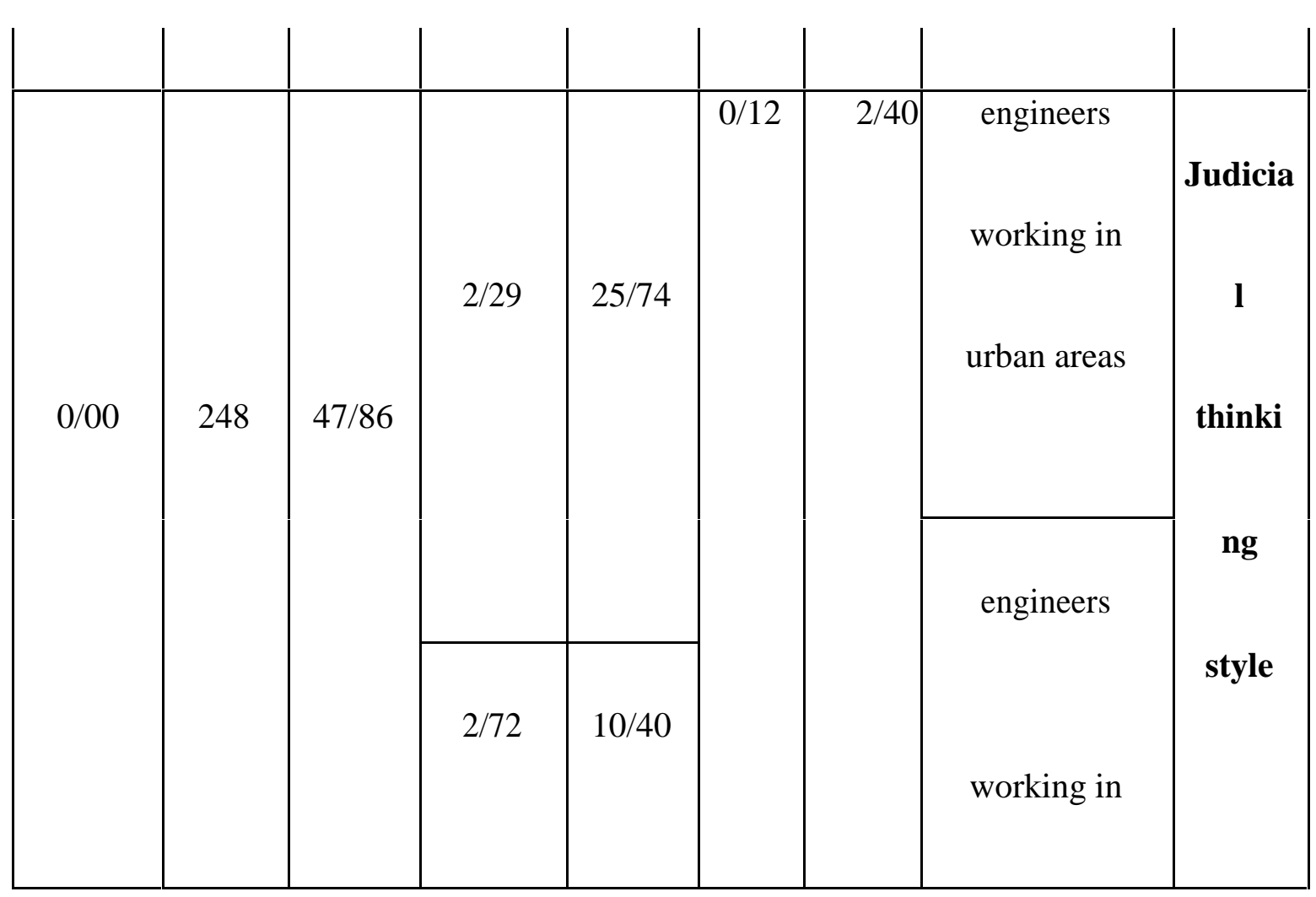

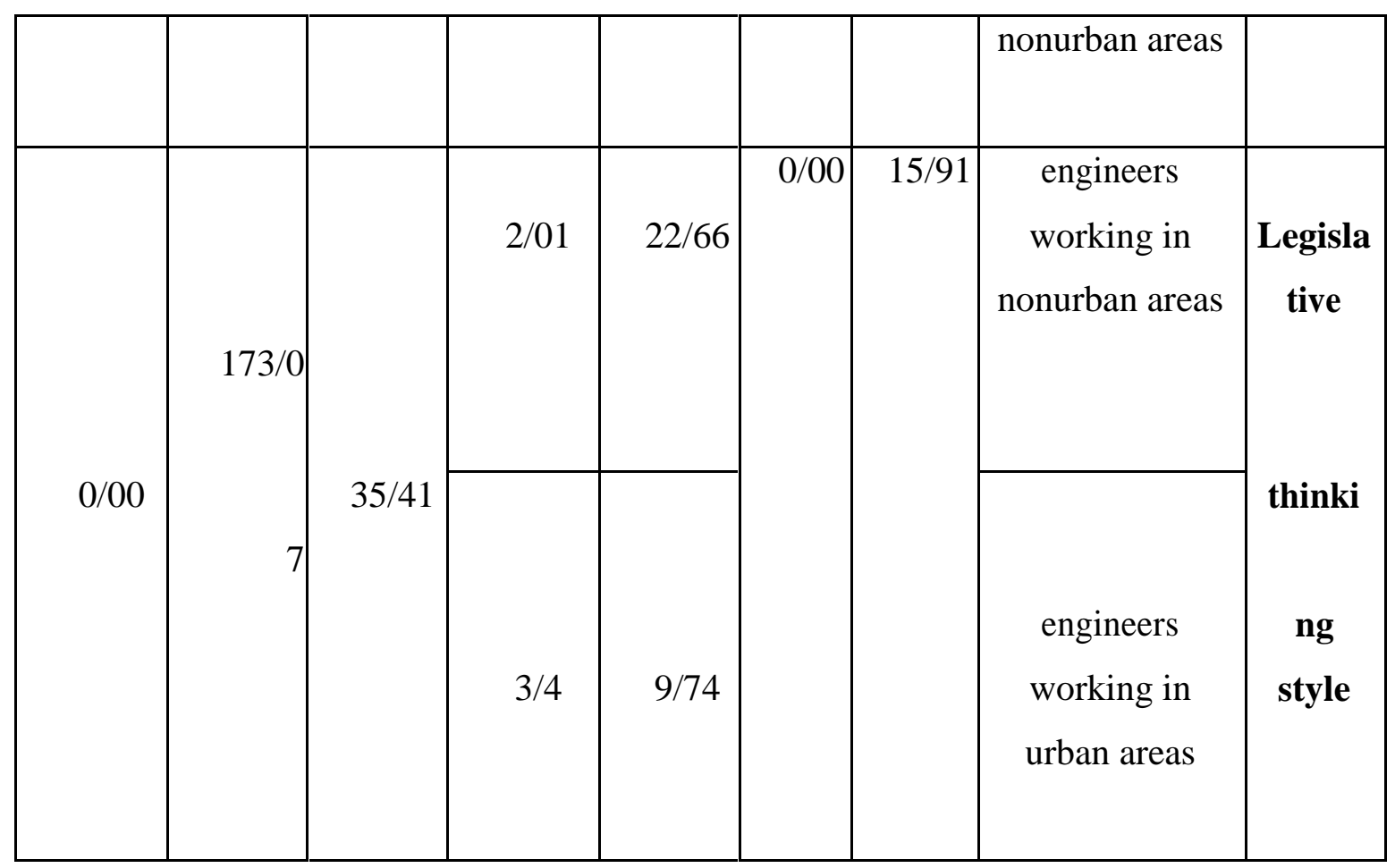

According to the significance level of Loon test that is higher than (0/05), assuming the equality of variance between the groups is confirmed. Therefore, in order to analyze the data of executive and judicial thinking styles, first row t-test data and for legislative thinking style, 
second row t-test data were used. As a result, there is a significant difference between the thinking styles of engineers working in urban areas and engineers working in nonurban areas.

\section{DISCUSSION AND CONCLUSION}

The purpose of the present study was to compare different thinking styles and marital satisfaction among engineers of urban and nonurban areas. The first purpose was to determine and compare the mean scores of marital satisfaction in two groups and there was a significant difference. Therefore, it clarifies that the marital satisfaction of engineers working in urban areas was better than those working in nonurban areas. The second purpose of this study was to determine and compare the mean scores of thinking styles of the two groups. Again, a significant difference was observed. The results of this study are consistent with the results of studies by Chang (2012), Gold et al. (1996), Lemir et al. (2007), Hill et al. (2008), Felt et al. (2002), Davis et al. (2003), Shfi'abadi et al. (2015), Najafabadi et al. (2010), Keshavarz et al.(2015).

About this case that why those engineers who are working in nonurban areas have worse conditions in marital satisfaction and thinking styles, the following interpretation can be presented: those engineers who are working out of cities are in a place which is full of environmental pollution, high amount of work, high working hours, tiresome work, work speed, being careful and sensitive in work, discomfort of cold and heat in workplace, job insecurity, the lack of appropriate stuff and job responsibilities accompanied by roles and responsibilities of home. Therefore, it is suggested to consider the following factors in order to reduce the amount of job burnout and increase the health of engineers; specially, those who are working in nonurban areas. Also, informing engineers and encouraging them to express the problems available in workplace and finding a way to solve them, conducting more studies on job burnout among engineers and providing applicable solutions to reduce the stressful factors, strengthening work medication in order to identify harmful agents of workplace and providing solutions to prevent mental disorders and factors leading to burnout, frequent and regular medical and psychiatric examinations in order to carefully identify endangered engineers in unpleasant environments, identifying burnt out engineers and providing counseling services for their treatment, providing employment benefits such as insurance, rewarding engineers to motivate them, changing the mental and physical conditions of engineers, using relaxation techniques, exercise and proper diet in order to enhance the mental health of individuals. Generally, researchers propose that the officials of this field must pay special attention to this problem and according to the above mentioned methods for 
reducing job burnout, design and implement some programs.

\section{REFERENCES}

[1] Alborzi, s., ostovar, s.thinking styles of gifted and nongifted students in iran, psychology rep. 2007, $100(3$ pt 2); 1076-82.

[2] Castles, M. Communication era: economy, society and culture-identification power (translated by Hasan Chavoshian). Tehran, Tarh-E-No, 2001.

[3] Corey, M.N.S., Corey, G. Becoming a haply, 1st ed. Pacific Grove CA: Brooks/Cole publishing Company, 1998.

[4] Danielson, R.L., \& Delisi, P.S. Thinking styles of American in exectives Santa Clara University. R. Danielson@ Scu.edu, 408-554, 2001.

[5] Dennerstein L, Koochaki P, Barton I, Graziottin A. Hypoactive sexual desire disorder in menopausal women: A survey of Western European women. J Sexual Med. 2006, 3(2), 212-22.

[6] Farhoodian, A. Flexibility, consistency and psychological signs. Cognitive Science News, Seventh year; 1, 74-75, 2005.

[7] Feresat, Z. Examining and comparing control and marital satisfaction among working women and household women of Tehran. M.A thesis. Tarbiat Moalem University, 2002.

[8] Ford, C.M. Interpretive Style, Motivation, Ability and Context as Pridictors of Creative Performance. Blackwell Publishers Ltd. 1999, 8(3).

[9] Fouladi, E. Counselling: perspectives, mental health concepts and skills. Third publication, Tehran: Toloo' publications, 2004.

[10]Freudenberger H. J.Staff Burn Out. Journal of Social Issues, 1974, 30, 159-165.

[11]Guttman, J. Why successful marriage, Why unsuccessful marriage. Translated by Mehrdad Firouzbakht. Tehran: Abjad publications; 1, 1998.

[12] Harrison, A.F., \& Bramson, R.M. The art of thinking. Berkley Publishing Group, 2002.

[13] Mehdad, A. Organizational and industrial psychology, first publication, Tehran, Jangal publications, 2002.

[14] Shifren JL, Monz BU, Russo PA, Segreti A, Johannes CB. Sexual problems and distress in United States women: prevalence and correlates. Obstetrics and gynecology, 2008, 112(5), 970-8.

[15] Sternberg, R. Thinking Styles (translated by Alaeddin E'temadi and Aliakbar Khosravi). Teharan; Dadar publcations, 2002.

[16] Yeh HC, Lorenz FO, Wickrama KA, Conger RD, Elder GH, Jr. Relationships among 
sexual satisfaction, marital quality, and marital instability at midlife. J Fam Psychol. 2006, 20(2), 339-43.

[17] Shahi, A., Ghafari, E., Ghasemi, Kh. The relationship between mental health and marital satisfaction of spouses. Kermanshah, 2011, 15(2), 119-126.

[18]Shfi'abadi, A., Soodani, M. The relationship between health and job burnout of Behbahan Islamic Azad University staff, Journal of thought and behavior; 2008, 10, 99107. Sternberg, R. J., Thinking Styles, New York: Cambridge University Press, 1997.

[19] Sternberg, R. J., Thinking Styles: Theory and Assessment at the Interface between Intelligence and Personality, Cambridge University Press, 1994.

\section{How to cite this article:}

Asrami Y. Comparing different thinking styles and marital satisfaction among engineers of urban and nonurban areas. J. Fundam. Appl. Sci., 2016, 8(2S), 685-696. 